\title{
Tolvaptan, hyponatremia, and heart failure
}

This article was published in the following Dove Press journal: International Journal of Nephrology and Renovascular Disease 30 March 201 I

Number of times this article has been viewed

\author{
Hammam D Zmily' \\ Suleiman Daifallah ${ }^{2}$ \\ Jalal K Ghali3 \\ 'Wayne State University/Detroit \\ Medical Center, Detroit, MI, USA; \\ 2John D Dingell VA Medical Center, \\ Detroit, MI, USA; ${ }^{3}$ Detroit Medical \\ Center, Detroit, MI, USA
}

Correspondence: Jalal K Ghali Detroit Medical Center, Harper University Hospital, 3990 John R, Suite 9370, Detroit, MI 4820I, USA $\mathrm{Tel}+|3| 3745706$ |

Email jghali@dmc.org
Abstract: Tolvaptan is the first FDA-approved oral $\mathrm{V}_{2}$ receptor antagonist for the treatment of euvolemic and hypervolemic hyponatremia, in patients with conditions associated with free water excess such as heart failure, cirrhosis, and the syndrome of inappropriate antidiuretic hormone secretion. Tolvaptan inhibits the binding of arginine vasopressin to the $\mathrm{V}_{2}$ receptors on the collecting ducts of the kidneys resulting in aquaresis, the electrolytes sparing excretion of water. This article reviews the accumulated experience with tolvaptan and all the major clinical trials that were conducted to study its safety and efficacy and concludes by summarizing clinicians' views of its current application in clinical practice.

Keywords: arginine vasopressin antagonist, tolvaptan, heart failure, hyponatremia

\section{Introduction}

Hyponatremia is the most common electrolyte abnormality seen in hospitalized patients ${ }^{1}$ and is associated with increased morbidity that includes cognitive impairment, ${ }^{2}$ falls, ${ }^{2}$ fractures, and osteoporosis; $;{ }^{3-5}$ longer hospital stay; and increased mortality. ${ }^{1,6-8}$ It is traditionally defined as serum $\mathrm{Na}^{+} \leq 135 \mathrm{mEq} / \mathrm{L} .{ }^{1}$ However, serum $\mathrm{Na}^{+}$concentration $\leq 138 \mathrm{mEq} / \mathrm{L}$ was found to be associated with worsened outcome, ${ }^{6-9}$ so hyponatremia should be redefined as serum $\mathrm{Na}^{+}$concentration $\leq 138 \mathrm{mEq} / \mathrm{L} .{ }^{10}$

Since $\mathrm{Na}^{+}$is the major determinant of plasma osmolality, hyponatremia is usually associated with hyposmolality. It may present as euvolemic hyponatremia as seen in the syndrome of inappropriate antidiuretic hormone secretion (SIADH), or hypervolemic hyponatremia in edema-forming conditions such as heart failure (HF) or cirrhosis. Hypovolemic hyponatremia is due to conditions promoting renal or extra-renal $\mathrm{Na}^{+}$loss. ${ }^{1}$

The clinical manifestations of hyponatremia include malaise, headache, nausea, vomiting, lethargy, confusion, stupor, seizure, and coma, depending on the severity of hyponatremia and the rapidity of its development. ${ }^{1}$ However, hyponatramic patients frequently have subtle symptoms, and are often perceived as asymptomatic, which explains why hyponatremia is frequently undiagnosed and untreated. ${ }^{11}$

Given the limitations to the traditional treatment of hyponatremia, fluid restriction with or without the use of lithium, demeclocycline, and urea, the introduction of vasopressin antagonists with their ability to induce aquaresis, the electrolyte free excretion of water, has provided an attractive option to the treatment of hyponatremia by directly opposing the action of arginine vasopressin (AVP). 


\section{Arginine vasopressin and its receptors}

AVP is a peptide hormone composed of 9 amino acids that plays a major role in preserving water balance, osmolality, and blood volume. It is synthesized in the hypothalamus, stored in the posterior pituitary gland, and then released as needed into the hypophyseal portal vein. ${ }^{11}$

Under normal conditions, the release of AVP is controlled primarily by osmolality. Osmoreceptors located in several areas of the brain are very sensitive to changes in serum osmolality. A rise in serum osmolality by $1 \%$ will stimulate the release of AVP, and in sequence increase water re-absorption at the renal tubule, causing water retention. ${ }^{12,13}$

Change in the circulating blood volume is the second mechanism by which AVP is stimulated. The baro-receptors in the carotid sinus and stretch receptors in the wall of the great veins, atria, and pulmonary trunk are sensitive to changes in the volume status (eg, volume depletion and/or hypotension). ${ }^{14,15}$ As low as $5 \%$ to $10 \%$ decrease in blood volume will lead to AVP release and subsequent water retention to restore the intravascular volume. ${ }^{14,15}$ This occurs in conditions characterized by arterial under-filling, such as HF due to low cardiac output and liver cirrhosis due to vasodilatation.

The release of AVP is accounted for predominantly by the above 2 mechanisms, but its secretion is also affected by other factors including endogenous angiotensin II, stress, and pain. ${ }^{15,16}$

AVP receptors are G protein-coupled receptors that mediate cardiovascular and renal functions. There are 3 subtypes $\left(\mathrm{V}_{1 \mathrm{~A}}, \mathrm{~V}_{2}\right.$, and $\left.\mathrm{V}_{1 \mathrm{~B}}\right)$. Table 1 summarizes the location and functions of the different receptors. ${ }^{17-20}$

\section{Arginine vasopressin antagonists}

The first non-peptide AVP antagonist was discovered in 1992 and subsequently several had been developed. ${ }^{21}$ By binding to the $\mathrm{V}_{2}$ receptors, they prevent the cascade leading to the insertion of aquaporin 2 (AQP-2) water channels into the luminal membrane of the principal cells and water reabsorption. ${ }^{19}$ Conivaptan is the first intravenous dual $\mathrm{V}_{1 \mathrm{~A}} / \mathrm{V}_{2}$ receptor antagonist approved by the US Food and Drug Administration (FDA) and tolvaptan is the first oral antagonist.

\section{Tolvaptan}

Tolvaptan (OPC-41061) is a potent, orally active, non-peptide $\mathrm{V}_{2}$ receptor antagonist. It was the first oral AVP receptor antagonist to be approved (in May 2009) by the FDA for the treatment of hypervolemic or euvolemic hyponatremia (associated with HF, cirrhosis, or SIADH) with either a serum $\mathrm{Na}^{+}$concentration $<125 \mathrm{mEq} / \mathrm{L}$ or less marked hyponatremia that is symptomatic and resistant to fluid restriction. ${ }^{20}$ It is produced by Otsuka Pharmaceutical Co Ltd, Rockville, MD and is available under the brand name Samsca ${ }^{\circledR} .22$

\section{Pharmacokinetics and pharmacodynamics}

Tolvaptan is a selective $V_{2}$ receptor antagonist with an affinity for the $\mathrm{V}_{2}$ receptor that is 1.8 times that of native AVP. Tolvaptan's affinity for the $V_{2}$ receptor is 29 times greater than its affinity for the $\mathrm{V}_{1 \mathrm{~A}}$ receptor. ${ }^{23}$

The pharmacokinetics of tolvaptan have been studied in healthy subjects at different single or multiple daily doses of up to $480 \mathrm{mg}$. For single oral doses ranging from 60 to $480 \mathrm{mg}$, the area under the curve (AUC) increases proportionally with dose. The apparent clearance was independent of the dose at clinically used doses. ${ }^{24}$

The time to peak concentration $\left(\mathrm{T}_{\text {max }}\right.$ ) was observed $\approx 2$ to 4 hours post-dose. The absolute bioavailability of tolvaptan is unknown, but at least $40 \%$ of the dose is absorbed as tolvaptan or metabolites, and its absorption is not affected by food intake. Tolvaptan is highly bound to plasma protein (99\%), and its volume of distribution is about $3 \mathrm{~L} / \mathrm{kg}$ in healthy subjects, and slightly higher in patients with $\mathrm{HF}^{25} \mathrm{The}$ estimated $t_{1 / 2}$ of tolvaptan is slightly shorter than 12 hours. ${ }^{20}$

From 0 to 12 hours post-dose, mean urine volume, free water clearance, and urine osmolality were similar for

Table I Arginine vasopressin receptors ${ }^{18-21}$

\begin{tabular}{lll}
\hline Receptor & Location & Function \\
\hline $\mathrm{V}_{\mathrm{IA}}$ & Vascular smooth muscle cells, hepatocytes, & Vasoconstriction, glycogenolysis, platelet aggregation, and myocytes \\
& platelets, uterus, renal, adrenal, and brain cells. & hypertrophy. \\
$\mathrm{V}_{\mathrm{IB}}$ & Anterior pituitary gland & Mediate the release of adrenocorticotropin hormone and endorphines. \\
$\mathrm{V}_{2}$ & Collecting ducts of the kidney. & Mediate free water absorption by mobilizing intracellular vesicles of aquaporin-2 \\
& & (AQP2) to the apical plasma membrane of the collecting duct cells, causing an \\
& increase in water permeability and antidiuretic effect. \\
\hline
\end{tabular}


all doses, but 12 to 24 hours post dose, the mean free water clearance generally increased with increasing dose, and urine osmolality decreased with increasing dose. ${ }^{24}$ Throughout the 0 - to 24-hour period, increases were seen in mean serum $\mathrm{Na}^{+}$concentration $(\sim 4-6 \mathrm{mEq} / \mathrm{L})$, plasma osmolality $(\sim 8 \mathrm{mOsm} / \mathrm{kg})$, and free water clearance $(\sim 6 \mathrm{~mL} / \mathrm{min})$; while mean urine concentration of $\mathrm{Na}^{+}$and potassium $\left(\mathrm{K}^{+}\right)$ were decreased to less than $20 \mathrm{mEq} / \mathrm{L}$ with no change in the serum $\mathrm{K}^{+}$concentration. ${ }^{24} \mathrm{Co}$-administration of tolvaptan and furosemide produced a higher increase in urine volume and free water clearance, a greater decrease in urinary osmolality, and no further increase in rennin activity and aldosterone concentration, compared with furosemide alone. ${ }^{26}$

\section{Drug formulation and dosing}

Tolvaptan is present in tablet form with different shapes according to the dosage. It is available in 15, 30, and $60 \mathrm{mg}$ strengths. It should be stored at controlled room temperature between $59^{\circ}$ and $86^{\circ} \mathrm{F}\left(15-30^{\circ} \mathrm{C}\right)$ and can be administered with or without food. ${ }^{22}$ The recommended starting dose is $15 \mathrm{mg} /$ day, which may be increased at intervals $\geq 24$ hour to $30 \mathrm{mg} / \mathrm{day}$, and to a maximum of $60 \mathrm{mg} /$ day.

Close monitoring of the serum $\mathrm{Na}^{+}$and volume status is a necessity to avoid complication from rapid correction of hyponatremia (eg, osmotic demyelination). Fluid restriction should be avoided during the first 24 hours of therapy, and patients should be advised to continue fluid ingestion in response to thirst.

\section{Metabolism and drug interaction}

Tolvaptan is metabolized mainly in the liver, primarily by cytochrome $\mathrm{P} 450$ (CYP 3A), and $<1 \%$ is excreted unchanged in the urine. ${ }^{24}$ The co-administration of tolvaptan with ketoconazole or other strong CYP 3A inhibitor (eg, clarithromycin, itraconazole, telithromycin, saquinavir, nelfinavir, ritonavir, and nefazodone) decreases the total clearance of tolvaptan and increases tolvaptan concentrations. The co-administration of grapefruit juice and tolvaptan results in a 1.8-fold increase in tolvaptan exposure. ${ }^{27}$ On the other hand, the co-administrations of tolvaptan with rifampin or other CYP $3 \mathrm{~A}$ inducers (eg, rifabutin, rifapentin, barbiturates, phenytoin, carbamazepine, and St John's Wort) results in increased metabolism of tolvaptan, which decreases its effects. ${ }^{20,28}$

Tolvaptan shows no significant pharmacokinetic interactions with amiodarone, warfarin, furosemide, or hydrochlorothiazide..$^{29,30}$ Also, there was no clinically relevant change in lovastatin or digoxin effects when co-administered with tolvaptan. ${ }^{28,31}$

\section{Contraindications, precautions, and side effects}

Tolvaptan is contraindicated with the use of a strong CYP $3 \mathrm{~A}$ inhibitor due to drug interaction. It is also contraindicated in hypovolemic hyponatremia because it might precipitate hypotension and renal failure. It should not be administered in anuric patients due to expected lack of clinical benefit. Patients who are unable to sense or appropriately respond to thirst stimulation should not take tolvaptan because this increases the risk of rapid correction of serum $\mathrm{Na}^{+}$.

Tolvaptan use in pregnancy is category $\mathrm{C}$, so it should be used only if the potential benefit justifies the potential fetal risk, and it is excreted into the milk of lactating rats, so that mothers should discontinue nursing or stop tolvaptan.

The FDA has restricted the initiation and re-initiation of tolvaptan to the hospital setting, where the serum $\mathrm{Na}^{+}$can be monitored closely. Since rapid correction of hyponatremia ( $>12 \mathrm{mEq} / \mathrm{L} /$ day) may cause osmotic demyelination resulting in severe neurological complications and possible death, caution should be advised with concomitant use of tolvaptan and hypertonic saline.

The most common adverse reactions (incidence $\geq 5 \%$ ) when tolvaptan was administered at a dose ranging from 15 to $60 \mathrm{mg} /$ day, were thirst, dry mouth, asthenia, constipation, polyuria, and hyperglycemia. ${ }^{22}$

Constipation, diarrhea, esophageal varices, thirst, malaise, pyrexia, increased blood uric acid and glucose, anorexia, insomnia, pollakiuria, nausea, vomiting, cough, hypo- and hyperkalemia, hypotension, dizziness, chest pain, anemia, headache, urinary tract infection, renal failure, pneumonia, ventricular tachycardia, atrial fibrillation, pain in extremity, and dry skin and mouth were side effects reported in clinical trials. ${ }^{32,33}$

\section{Tolvaptan in the treatment of hyponatremia}

Given the aquaretic effect of tolvaptan, initial clinical trials assessed its role in the management of hyponatremia. In order to compare tolvaptan to fluid restriction for the management of euvolemic and hypervolemic hyponatremia, a multicenter, prospective, randomized, open-label, active-controlled, dose titration trial was conducted. ${ }^{34}$ Hyponatremic patients with serum $\mathrm{Na}^{+}$concentration $<135 \mathrm{mEq} / \mathrm{L}$ for 2 or more consecutive days were eligible (Table 2).

The primary outcome was normalization of serum $\mathrm{Na}^{+}$ concentration ( $\geq 135 \mathrm{mEq} / \mathrm{L}$ or $\geq 10 \%$ increase in serum $\mathrm{Na}^{+}$ level from baseline to the last inpatient assessment). 
Table 2 Tolvaptan studies in hyponatremic patients

\begin{tabular}{|c|c|c|c|c|}
\hline $\begin{array}{l}\text { Reference } \\
\text { Design }\end{array}$ & Intervention & $\begin{array}{l}\text { Patient } \\
\text { population }\end{array}$ & Major measures & Major results \\
\hline $\begin{array}{l}\text { Multicenter, } \\
\text { prospective, } \\
\text { randomized, } \\
\text { open-label, } \\
\text { active-controlled, } \\
\text { dose titration }{ }^{34}\end{array}$ & $\begin{array}{l}\text { Patients were } \\
\text { randomized } \\
\text { to tolvaptan } \\
\text { or fluid } \\
\text { restriction } \\
\text { with placebo }\end{array}$ & $\begin{array}{l}\mathrm{n}=28 \\
\text { Hyponatremic } \\
\text { patients with } \\
\text { serum } \mathrm{Na}^{+} \\
\text {concentration } \\
<135 \mathrm{mEq} / \mathrm{L}\end{array}$ & $\begin{array}{l}\text { Normalization } \\
\text { of serum } \mathrm{Na}^{+} \\
\text {concentration }\end{array}$ & $\begin{array}{l}\text { A total of I I patients normalized their } \mathrm{Na}^{+} \text {levels } \\
\text { by the last inpatient visit in the tolvaptan group } \\
\text { compared to } 3 \text { patients in the placebo group } \\
(P=0.049) \\
50 \% \text { of the patients achieved normalization in their } \\
\mathrm{Na}^{+} \text {level within } 4 \text { days in the tolvaptan group } \\
\text { compared to } 8 \text { days in the fluid restriction group } \\
(P<0.03) \\
\text { Tolvaptan patients had significantly larger increases } \\
\text { in mean serum } \mathrm{Na}^{+} \text {from baseline }\end{array}$ \\
\hline $\begin{array}{l}\text { Two randomized, } \\
\text { double-blind, } \\
\text { placebo-controlled, } \\
\text { Phase III trials }{ }^{35}\end{array}$ & $\begin{array}{l}\text { Patients were } \\
\text { randomized } \\
\text { to receive } 15 \mathrm{mg} / \text { day } \\
\text { of oral tolvaptan or } \\
\text { placebo for } 30 \text { days }\end{array}$ & $\begin{array}{l}\mathrm{n}=448 \\
\text { Euvolemic or } \\
\text { hypervolemic } \\
\text { hyponatremic } \\
\text { patients }\end{array}$ & $\begin{array}{l}\text { The change in the } \\
\text { average daily area } \\
\text { under the curve (AUC) } \\
\text { for the serum } \mathrm{Na}^{+} \\
\text {concentration from baseline } \\
\text { to day } 4 \text { and day } 30 \\
\text { The percentage of patients } \\
\text { with normalized serum } \\
\mathrm{Na}^{+} \text {concentration } \\
\text { at day } 4 \text { and } 30\end{array}$ & $\begin{array}{l}\text { Tolvaptan significantly increased the average daily } \\
\text { AUC for the serum } \mathrm{Na}^{+} \text {concentration from } \\
\text { baseline to study day } 4 \text { and during the entire } \\
30 \text {-day study period as compared with placebo } \\
\text { Significantly more patients in the tolvaptan group } \\
\text { had normal serum } \mathrm{Na}^{+} \text {concentration and fewer } \\
\text { patients had marked hyponatremia at day } 4 \text { and } \\
\text { day } 30 \text {, as compared with placebo }\end{array}$ \\
\hline $\begin{array}{l}\text { Open-label } \\
\text { extension } \\
\text { of the SALT-I } \\
\text { and SALT-2 trials }{ }^{36}\end{array}$ & $\begin{array}{l}\text { 4-year sequential, } \\
\text { open-label } \\
\text { extension of } \\
\text { the SALT-I } \\
\text { and SALT-2 trials }\end{array}$ & $\begin{array}{l}\mathrm{n}=\mathrm{I} \mathrm{I} \mathrm{I} \\
\text { Euvolemic or } \\
\text { hypervolemic } \\
\text { hyponatremic } \\
\text { patients }\end{array}$ & $\begin{array}{l}\text { Evaluate the safety } \\
\text { and efficacy of } \\
\text { long-term tolvaptan } \\
\text { use in hyponatremia }\end{array}$ & $\begin{array}{l}\text { Multiple adverse events were judged to be related } \\
\text { to tolvaptan }\end{array}$ \\
\hline $\begin{array}{l}\text { Post hoc analysis } \\
\text { on the SALT trials }{ }^{37}\end{array}$ & $\begin{array}{l}7 \text { patients were } \\
\text { randomized } \\
\text { to receive } \\
\text { tolvaptan and } \\
\text { I } 2 \text { to placebo }\end{array}$ & $\begin{array}{l}\mathrm{n}=19 \\
\text { Schizophrenic } \\
\text { patients } \\
\text { with idiopathic } \\
\text { hyponatremia }\end{array}$ & $\begin{array}{l}\text { Evaluate the effects } \\
\text { of tolvaptan } \\
\text { on idiopathic } \\
\text { hyponatremia in } \\
\text { schizophrenia }\end{array}$ & $\begin{array}{l}\text { Tolvaptan patients had significantly greater } \\
\text { increase in the average daily AUC for } \mathrm{Na}^{+} \\
\text {concentration from baseline to day } 4 \text {, as compared } \\
\text { with placebo } \\
\text { Mean serum } \mathrm{Na}^{+} \text {concentrations were significantly } \\
\text { higher at all measurement times after receiving the } \\
\text { study medication except at } 8 \text { hours, where it was } \\
\text { marginally different }(P=0.07)\end{array}$ \\
\hline
\end{tabular}

After 2-day placebo run-in period, patients were randomized to tolvaptan or fluid restriction with placebo in a 2:1 ratio for the duration of their inpatient stay or 12 days, whichever occurred first. Tolvaptan was started at $10 \mathrm{mg}$ /day with daily incremental increases to $15,30,45$, and $60 \mathrm{mg} /$ day as needed to achieve a normal serum $\mathrm{Na}^{+}$ level. Fluid restriction was started at $1200 \mathrm{~mL} /$ day in the placebo group, and adjusted by the investigator to achieve normal serum $\mathrm{Na}^{+}$levels. The study treatment was continued during the outpatient maintenance period if serum $\mathrm{Na}^{+}$ level normalized before day 14 , otherwise subjects could be withdrawn to allow physicians to administer other treatments. The tolvaptan dose or the placebo dose with fluid restriction was maintained at the same level throughout the maintenance period (days 15-28).

A total of 28 patients were enrolled in the study; 17 were randomized to tolvaptan, and 11 to placebo with fluid restriction. Patients were $66 \pm 13$ and $67 \pm 9$ years of age (mean $\pm \mathrm{SD}$ ) in the tolvaptan and placebo groups, respectively. Women were $41 \%$ and $45 \%$ in the tolvaptan and placebo groups, respectively. HF was the cause of hyponatremia in 50\%, 14\% had cirrhosis, and 36\% had SIADH or other cause. The mean $( \pm \mathrm{SD})$ baseline serum $\mathrm{Na}^{+}$levels were $129 \pm 3 \mathrm{mEq} / \mathrm{L}$ (tolvaptan), and $129 \pm 4 \mathrm{mEq} / \mathrm{L}$ (placebo). In the tolvaptan group, 2 out of the 17 patients were withdrawn during the run-in period because of protocol violations or meeting withdrawal criteria. The remaining 15 patients received tolvaptan, but only 12 completed the treatment period and received the study drug during the maintenance period, the rest had adverse events preventing them from completing the study. Only 6 patients completed the 28-day outpatient maintenance period, the other 6 patients were withdrawn due to adverse events (1 patient), losing follow up (1 patient), meeting withdrawal criteria (2 patients), and withdrawing consent due to personal reasons ( 2 patients). In the placebo group, 3 out of the 11 patients were withdrawn 
during the run-in period because of protocol violations or meeting withdrawal criteria. The remaining 8 patients received placebo and were placed on fluid restriction; however only 2 patients completed the treatment period and both of them completed the 28-day outpatient maintenance period. The other 6 patients were withdrawn due to adverse events ( 2 patients), insufficient response ( 1 patient), meeting withdrawal criteria (1 patient), and withdrawing consent due to lack of effect (2 patients).

The mean \pm SD dose of tolvaptan was $26 \pm 15$ and $28 \pm 18 \mathrm{mg} /$ day during the initiation phase and maintenance phase, respectively. The mean $\pm \mathrm{SD}$ duration of treatment with tolvaptan was $7 \pm 3.6$ and $14 \pm 8$ days in the initiation phase and maintenance phase, respectively. Tolvaptan patients had significantly larger increases in mean serum $\mathrm{Na}^{+}$from baseline, which was observed as early as 4 hours after the first dose, reached plateau by day 5 , and persisted through the last inpatient visit, compared with fluid restriction patients. The mean $\pm \mathrm{SD}$ change in serum $\mathrm{Na}^{+}$level was $4.7 \pm 3.1$ and $-0.3 \pm 4$ in the tolvaptan and placebo groups, respectively $(P=0.039)$. A total of 11 patients normalized their $\mathrm{Na}^{+}$levels by the last inpatient visit in the tolvaptan group compared with 3 patients in the placebo group $(P=0.049)$. Half the patients $(50 \%)$ achieved normalization in their $\mathrm{Na}^{+}$ level within 4 days in the tolvaptan group compared with 8 days in the fluid restriction group $(P<0.03)$.

As expected, urine output was significantly higher in the tolvaptan group at baseline and at the last inpatient day compared with fluid restriction group. No differences in serum $\mathrm{K}^{+}$, blood pressure, heart rate, thirst score, or adverse effects requiring drug discontinuation were observed between the 2 groups.

This study showed that tolvaptan without fluid restriction was more effective than fluid restriction alone in normalizing hyponatremia. However it is limited by small sample size, the number of subjects who withdrew early, and the short-term follow up.

The SALT-1 and SALT-2 trials (Study of Ascending Levels of Tolvaptan in Hyponatremia 1 and 2) are 2 relatively large, randomized, double-blind, placebo-controlled, phase III trials conducted to evaluate the effect of tolvaptan on euvolemic and hypervolemic hyponatremic patients (Table 2). ${ }^{35}$

Patients with euvolemic or hypervolemic hyponatremia (serum $\mathrm{Na}^{+}$concentration $<135 \mathrm{mEq} / \mathrm{L}$ ) were included. Exclusion criteria included psychogenic polydipsia, head trauma, postoperative conditions, uncontrolled hypothyroidism or adrenal insufficiency, any hyponatremic condition associated with the use of medications that can be safely stopped, or hypovolemic hyponatrmia.
The patients were randomized to receive $15 \mathrm{mg} /$ day of oral tolvaptan in the morning or matching placebo for 30 days. Fluid restriction was not mandatory, but treatment with lithium, demeclocycline, or urea was not permitted. The tolvaptan dose was adjusted to maintain a serum $\mathrm{Na}^{+}$concentration between 135 and $145 \mathrm{mEq} / \mathrm{L}$, per study protocol. Patients were hospitalized the first day of the study and the majority were discharged by day 4 .

Patients' evaluation was conducted at baseline, 8 hours after drug administration, and in days 2, 3, 4, 11, 18, 25, 30, and 37 . The study medication was stopped at 30 days, and the effect of discontinuation was studied on the last evaluation (day 37). The 2 primary end points of the study were: the change in the average daily AUC for the serum $\mathrm{Na}^{+}$ concentration from baseline to day 4 and day 30 . Secondary outcomes included the change in the AUC for serum $\mathrm{Na}^{+}$ concentration in patients with marked hyponatremia, the absolute serum $\mathrm{Na}^{+}$concentration at each visit, the time to normalization of serum $\mathrm{Na}^{+}$concentration, the percentage of patients with normalized serum $\mathrm{Na}^{+}$concentration at day 4 and 30, the categorical serum $\mathrm{Na}^{+}$concentration at day 4 and 30 (normal, $>135 \mathrm{mEq} / \mathrm{L}$; mild hyponatremia, 130-135 mEq/L; or marked hyponatremia, <130 mEq/L), fluid intake and output at day 1, change in body weight in hypervolemic patients at day 1 , fluid restriction or use of rescue intravenous saline, and the change in scores on the physical component summary and mental component summary of the medical outcomes study 12-item short-form (SF-12) general health survey.

In the SALT-1 trial, 205 patients were randomized; 102 patients received tolvaptan, and 103 patients received placebo. The percentage of patients who completed the trial (30-day study period and 7-day follow up) was $77.5 \%$ in the tolvaptan group and $63.1 \%$ in the placebo group. Mean $( \pm \mathrm{SD})$ age was $60 \pm 14$ and $60 \pm 13$ in the tolvaptan and placebo groups, respectively. Females were $49 \%$ and $40 \%$ in the tolvaptan and placebo groups, respectively. In the SALT-2 trial, 243 patients were randomized; 123 patients received tolvaptan, and 120 patients received placebo. The percentage of patients who completed the trial was $74.8 \%$ in the tolvaptan group and $74.2 \%$ in the placebo group. Mean $( \pm \mathrm{SD})$ age was $62 \pm 15$ and $63 \pm 14$ in the tolvaptan and placebo groups, respectively. Females were $39 \%$ in both tolvaptan and placebo groups. The patients' demographic and baseline characteristics were similar in the study groups of both trials.

Tolvaptan significantly increased the average daily AUC for the serum $\mathrm{Na}^{+}$concentration from baseline to study day 4 and during the entire 30-day study period compared 
with placebo. Tolvaptan significantly increased serum $\mathrm{Na}^{+}$ concentration within 8 hours of administration compared with placebo, in both trials. This statistical superiority was maintained at all subsequent visits. With tolvaptan, the serum $\mathrm{Na}^{+}$concentration approached the normal range more rapidly, compared with placebo in both trials. At day-37, after discontinuation of the study medication, there was no statistical difference in serum $\mathrm{Na}^{+}$concentration in both SALT-1 and SALT-2 trials.

In both trials, significantly more patients in the tolvaptan group had normal serum $\mathrm{Na}^{+}$concentration and fewer patients had marked hyponatremia at day 4 and day 30, compared with placebo. On day-30, scores on the physical component summary of the SF-12 health survey did not differ significantly between the groups in both trials. However, the mental component summary improved in the tolvaptan group in the combined analysis of both trials $(P=0.02)$, in SALT-1 $(P=0.04)$, and in the combined subgroup of marked hyponatremia $(P=0.04)$, but not in SALT-2 $(P=0.14)$.

In both trials, the following side effects were observed in the tolvaptan group: dehydration with hypotension, dehydration with dizziness, syncope, acute renal failure, ascites, increased serum $\mathrm{Na}^{+}$and creatinine concentrations, and $E$. coli sepsis with respiratory failure. In the tolvaptan group, eight patients were withdrawn from the study due to adverse events that were potentially related to the study treatment; rash, dysgeusia, nocturia, urinary frequency, exanthema, muscle weakness, and hypernatremia. The number of deaths in the 2 groups within the defined observation period was similar. In the tolvaptan group, only 4 patients exceeded the desirable rate of $\mathrm{Na}^{+}$correction during the first 24 hours ( $>0.5 \mathrm{mEq} / \mathrm{L} /$ hour), and the maximum observed rate was $0.61 \mathrm{mEq} / \mathrm{L} /$ hour. In the tolvaptan group, $1.8 \%$ of the patients had a serum $\mathrm{Na}^{+}$concentration $>146 \mathrm{mEq} / \mathrm{L} .{ }^{32}$

The 2 trials unequivocally proved that tolvaptan, when added to standard therapy, was superior to placebo in raising and maintaining serum $\mathrm{Na}^{+}$concentration in patients with euvolemic and hypervolemic hyponatremia of diverse etiologies. They also showed that the benefit was confined to its continuous usage without long lasting effect.

The SALTWATER trial (Safety and sodium Assessment of Long-term Tolvaptan With hyponatremia: A year-long, open-label Trial to gain Experience under Real world conditions) was a 4-year sequential, open-label extension of the SALT-1 and SALT-2 trials (Table 2). ${ }^{36}$ It was conducted to evaluate the safety and efficacy of long-term tolvaptan use in hyponatremia. Out of the 325 patients who completed the SALT-1 and SALT-2 trials, 111 were enrolled (38 patients from SALT-1, and 73 from SALT-2). In this study, $49.5 \%$ of the patients were men, and the mean $( \pm \mathrm{SD})$ age of patients was 64.6 \pm 15.0 . The median time from completion of SALT-1 and SALT-2 trials to enrollment in the SALTWATER was 30 days per patients. A total of 64 of the enrolled patients discontinued treatment during the follow up period for a variety of reasons. Mild hyponatremia was seen in $46.8 \%$ of the patients (serum $\mathrm{Na}^{+}$concentration between 130-134 mEq/L), and the rest had marked hyponatremia (serum $\mathrm{Na}^{+}$concentration $<130 \mathrm{mEq} / \mathrm{L}$ ) at baseline in SALT-1 and SALT-2. Upon enrollment in SALTWATER, $15.3 \%$ of the patients had normal serum $\mathrm{Na}^{+}$concentration, $53.2 \%$ had mild hyponatremia, and $31.5 \%$ had marked hyponatremia. HF was the etiology of hyponatremia in $29.7 \%$ of the patients, while cirrhosis accounted for $18.0 \%$, and SIADH and other causes were $52.3 \%$. The mean dose of tolvaptan was increased to $30 \mathrm{mg}$ /day during the first 16 to 20 weeks, and maintained at that level for the rest of the study period.

The patients were followed while they were on tolvaptan therapy for a mean of 701 days. During that time, 105 patients had adverse effects. Pollakiuria, thirst, fatigue, dry mouth, polydipsia, polyuria, hypotension, hypernatremia, dizziness, headache, peripheral edema, and acute renal failure were the most common adverse effects that were judged to be tolvaptan-related.

A total of 64 patients were withdrawn from the study. Adverse effects were the reason for withdrawal in 19 patients from which 6 patients died (cardiac failure, esophageal varices, hepatic cirrhosis, cerebral hemorrhage, and gastrointestinal hemorrhage). The adverse effects in the surviving 13 patients were ventricular tachycardia, vertigo, gastrointestinal hemorrhage, vomiting, gait disturbance, irritability, increase in serum creatinine or $\mathrm{Na}^{+}$, anorexia, bladder cancer, dysphasia, myocardial infarction, psychotic disorder, renal failure, and pruritus. Out of those, severe ventricular tachycardia, severe irritability, mild increase in serum $\mathrm{Na}^{+}$, mild anorexia, severe increase in serum creatinine, and moderate pruritus were judged to be possibly or probably related to tolvaptan.

An additional 13 patients died as an outcome of an adverse effect without being withdrawn from the study (cardiac failure, renal failure, respiratory failure, cardiac arrest, cardiorespiratory arrest, hepatorenal syndrome, pneumonia, cerebral hemorrhage, sepsis, and urosepsis), giving a total of 19 deaths. Out of the 19 patients who died, only the death of the patient with the severe hepatorenal syndrome was judged to be possibly related to tolvaptan. Five patients 
had $>1 \mathrm{mEq} / \mathrm{L} /$ hour increase in serum $\mathrm{Na}^{+}$concentration within the first 8 hours, and 18 patients had serum $\mathrm{Na}^{+}$ concentration $>145 \mathrm{mEq} / \mathrm{L}$ at individual time points ( 1 was withdrawn from the study, while the hypernatremia resolved in the other 17 patients).

Serum $\mathrm{Na}^{+}$concentration at baseline ranged between 114 and $141 \mathrm{mEq} / \mathrm{L}$ with a mean $( \pm \mathrm{SD})$ of $130.8 \pm 4.4 \mathrm{mEq} / \mathrm{L}$. Correction of serum $\mathrm{Na}^{+}$levels occurred at similar rates during the first 8 hours in SALTWATER and the SALT-1 and SALT-2, and by day 14 , serum $\mathrm{Na}^{+}$levels reached similar plateau. After the initial titration period, mean serum $\mathrm{Na}^{+}$levels remained normal throughout the study period ( $>4$ years). The rate of serum $\mathrm{Na}^{+}$correction was greater at the beginning in the subgroup of patients with marked hyponatremia, but similar kinetics were observed in the mild and marked hyponatremia groups, and in the HF and SIADH/other cause groups. Patients with cirrhosis had a trend of lower final serum $\mathrm{Na}^{+}$levels. More than $60 \%$ of the marked hyponatremia group and $45 \%$ of the mild hyponatremia group had normal $\mathrm{Na}^{+}$level by week 4 . Similar serum $\mathrm{Na}^{+}$level correction rates were observed in the HF and SIADH/other cause groups, whereas cirrhosis patients had lower rates.

Serum $\mathrm{Na}^{+}$levels declined in all patient subgroups by day 7 of withholding tolvaptan. The percentage of the patients who had $\geq 3 \mathrm{mEq} / \mathrm{L}$ drop in their $\mathrm{Na}^{+}$level with tolvaptan discontinuation was $68 \%$, and a similar proportion of patients dropped to $<135 \mathrm{mEq} / \mathrm{L}$. In the mild and marked hyponatremia subgroups, $122.3 \pm 184.3$ and $162.5 \pm 186$ days were the mean $( \pm \mathrm{SD})$ time for first fluid restriction, respectively. Fluid restriction was required in $13.2 \%$ and $5.4 \%$ of patients in the mild and marked hyponatremia subgroups, respective$1 y .{ }^{33}$ The study proved that the effect of tolvaptan on increasing serum $\mathrm{Na}^{+}$concentration was maintained long term, and although there were numerous adverse events the trial did not have a comparator group of an equally ill cohort treated with placebo over this long period of time.

Josiassen et al conducted a post hoc analysis on the SALT trials to evaluate the effects of tolvaptan on idiopathic hyponatremia in schizophrenia (Table 2). ${ }^{37}$ A total of 24 subjects in the SALT trials had schizophrenia or schizoaffective disorder, and 19 of them had idiopathic hyponatremia. The other 5 patients had HF (2 patients) or liver cirrhosis (3 patients) as a cause for their hyponatremia; hence they were excluded from this analysis. Out of the 19 subjects, 7 were randomized to receive tolvaptan and 12 to placebo. Mean age $( \pm \mathrm{SD})$ was $52.3 \pm 10.4$ and $49.6 \pm 10$ years in the tolvaptan and placebo groups, respectively. Males were $57.1 \%$ and $91.7 \%$ in the tolvaptan and placebo groups, respectively. The baseline characteristics of the 2 groups were similar except for the dose of antipsychotic medications which was higher in the tolvaptan group.

Tolvaptan patients had significantly greater increase in the average daily AUC for $\mathrm{Na}^{+}$concentration from baseline to day 4, compared with placebo (mean \pm SD were $5.14 \pm 3.14$ vs $0.91 \pm 2.6 \mathrm{mEq} / \mathrm{L}$, respectively, $P=0.0055)$. The same was also observed from baseline to day 30 ; $7.51 \pm 2.75 \mathrm{mEq} / \mathrm{L}$ (mean $\pm \mathrm{SD})$ in the tolvaptan group compared with $1.39 \pm 1.9 \mathrm{mEq} / \mathrm{L}$ (mean $\pm \mathrm{SD}$ ) in the placebo group $(P<0.001)$. Mean serum $\mathrm{Na}^{+}$concentrations were significantly higher at all measurement times after receiving the study medication except at 8 hours, where it was marginally different $(P=0.07)$. Subjects on higher doses of antipsychotic drugs showed greater improvement in their serum $\mathrm{Na}^{+}$concentration. Only 1 subject (on placebo) required fluid restriction, and no subject required rescue therapy or had excessive increase in serum $\mathrm{Na}^{+}$concentration.

No significant changes in serum creatinine or $\mathrm{K}^{+}$concentrations were noticed. In the tolvaptan group, 2 patients experienced dehydration and hypotension; 1 was judged to be unrelated to tolvaptan, and the other was transient and due to patient misunderstanding of fluid restriction. No long-term adverse effects were observed, and moreover, no adverse symptoms were noticed after drug discontinuation.

This study showed the feasibility of using tolvaptan as a treatment of hyponatremia in this special population. However, this is a post hoc analysis of the SALT trials, and it would be desirable to target this population in future prospective trials.

\section{Use of tolvaptan in heart failure}

The SALT trials were 2 of the major trials conducted to evaluate the effects of tolvaptan in hyponatremic patients. ${ }^{35}$ In both trials, HF was a major etiology for hyponatremia, accounting for $33 \%$ in the SALT- 1 , and $29 \%$ in the SALT- $2 .{ }^{35}$

Several randomized, double-blind studies were conducted in patients with HF to assess the effect of tolvaptan on congestion, hemodynamics, left ventricular remodeling, HF hospitalization, and survival.

A multicenter, randomized, double-blind, placebocontrolled trial was conducted to evaluate the effects of chronic tolvaptan use on congestion in patient with HF irrespective of their ejection fraction. Patients had to have HF symptoms for at least 30 days, and signs of volume overload at screening despite diuretic use for at least 30 days, with a fixed dose (40-240 mg) of furosemide for at least 7 days before enrollment. All patients received standard HF treatment. ${ }^{38}$ 
The primary outcome of the study was the change in body weight on day 14 from baseline. Secondary outcomes included ankle edema, urine $\mathrm{Na}^{+}$excretion, urine volume, and urine osmolality. Patients had 3-day run-in period (random assignment period) during which they were stratified for baseline furosemide dose (40-79 $\mathrm{mg}$ or $80-240 \mathrm{mg}$ ) and a separate random assignment was done in each stratum to maintain an overall balance between the different tolvaptan groups. After that period, they entered a 25-day treatment period in an outpatient setting. A total of 254 patients were enrolled in the study; 64, 64, 63, and 63 patients were randomized to 30,45 , or $60 \mathrm{mg}$ tolvaptan, or placebo, respectively. Mean $( \pm \mathrm{SD})$ ages were $67.6 \pm 10.9,65.6 \pm 13.1,68.5 \pm 13.6$, and $65.1 \pm 12.9$ in the 30,45 , and $60 \mathrm{mg}$ tolvaptan, and placebo, respectively. Men were $62.5,60.9,60.3$, and $73.0 \%$ in the 30,45 , and $60 \mathrm{mg}$ tolvaptan, and placebo, respectively. The percentage of patients completing the study was $87 \%$.

The patients were to return to the clinic on day 3, 4, 7, 10, 14,21 , and 28 during the treatment period. A dose-dependent, statistically significant, decrease in body weight from baseline was observed on the first day of tolvaptan treatment at all doses and maintained throughout the study, as compared with placebo. The decrease in body weight was similar in all tolvaptan patients irrespective of left ventricular ejection fraction. Urine volumes were 3909, 4232, 4597, and $2328 \mathrm{~mL}$ in the 30,45 , and $60 \mathrm{mg}$ tolvaptan, and placebo, respectively $(P<0.05$, compared with placebo). Despite the increase in fluid intake with tolvaptan therapy, the mean net fluid losses were significantly higher as compared with placebo; 1337 , 988, 1286, and $98 \mathrm{~mL}$ in the 30, 45, and $60 \mathrm{mg}$ tolvaptan, and placebo, respectively ( $P<0.05$ at each dose). Urine osmolality decreased to a mean \pm SD of $15.47 \pm 189.95$, $52.34 \pm 164.69$, and $118.77 \pm 131.66 \mathrm{mOsm} / \mathrm{kg}$ in the 30 , 45 , and $60 \mathrm{mg}$ tolvaptan groups, respectively, while an increase of $135.81 \pm 189 \mathrm{mOsm} / \mathrm{kg}$ was observed with placebo $(P<0.05)$. Tolvaptan was also associated with significantly higher total urinary $\mathrm{Na}^{+}$excretion and lower urine $\mathrm{Na}^{+}$concentrations compared with placebo $(P<0.05$ for both).

Small mean increases $(<4 \mathrm{mEq} / \mathrm{L})$ in serum $\mathrm{Na}^{+}$concentrations were observed with tolvaptan compared with small mean decreases $(<1 \mathrm{mEq} / \mathrm{L})$ with placebo. Serum $\mathrm{Na}^{+}$ concentrations remained within the normal limits in most of the tolvaptan-treated patients. Above normal increases in serum $\mathrm{Na}^{+}$concentration were seen in $6,11,13$, and $5 \%$ of the patients on 30,45 , and $60 \mathrm{mg}$ tolvaptan, and placebo, respectively, but did not require correction. The observed changes in serum $\mathrm{Na}^{+}$concentrations were significantly different between tolvaptan groups and placebo group at all times except for the $45 \mathrm{mg}$ group at day 25 . Hyponatremia was seen in $28 \%$ of the patients in this study (serum $\mathrm{Na}^{+}$ concentration $<136 \mathrm{mEq} / \mathrm{L}$ ), and those patients showed greater increases in serum $\mathrm{Na}^{+}$that remained within the normal range during the study (normalization was seen on day 1 in $80 \%$ of tolvaptan group vs $40 \%$ in placebo group, $P<0.05)$. However, normonatremic patients had an acute and transient increase in $\mathrm{Na}^{+}$levels, with values returning to baseline within 3 weeks of therapy. Normalization of serum $\mathrm{Na}^{+}$concentrations was maintained in $82 \%$ of tolvaptan group vs $40 \%$ of placebo group at the last treatment day $(P<0.05)$.

Statistically significant improvement in ankle edema was observed at all times with $45 \mathrm{mg}$ of tolvaptan compared with placebo $(P<0.05)$. No significant differences in the quality of life, heart rate, diastolic blood pressure, systolic blood pressure, serum $\mathrm{K}^{+}$concentrations, or renal function were observed between the placebo and tolvaptan groups. Dry mouth, thirst, polyuria, and urinary frequency were higher with tolvaptan.

This study suggests that tolvaptan decreases body weight, normalizes serum $\mathrm{Na}^{+}$concentration in patients with hyponatremia, and ameliorates edema in patients with chronic HF with mild signs of congestion on chronic diuretic therapy. However, this study was limited to patients with mild signs of congestion, and the results do not necessarily apply to all patients with HF. ${ }^{38}$

The Acute and Chronic Therapeutic Impact of a Vasopressin Antagonist in Congestive Heart Failure (ACTIV in CHF) is a multicenter, randomized, double-blind, placebocontrolled, parallel-group, dose-ranging, phase 2 feasibility trial that was conducted to evaluate the short-term and intermediate-term effects of tolvaptan in patients hospitalized with HF. ${ }^{39,40}$ Patients were included in the study if they were admitted for worsening HF, had left ventricular ejection fraction $<40 \%$ within 1 year of admission, and systemic congestion (jugular venous distention, rales, or peripheral edema) after initial in-hospital therapy for HF.

Patients were screened within 72 hours and randomized within 96 hours of admission if they continued to have signs and symptoms of congestion despite standard therapy (including diuretics) and were randomized in a 1:1:1:1 ratio to tolvaptan 30,60 , or $90 \mathrm{mg} /$ day or placebo. The study had an inpatient period (up to 10 days), and an outpatient period (7 weeks). Study drug was given daily at 9 am during the inpatient and outpatient periods. Patients were withdrawn from the study if they were hospitalized for $>10$ days after 
first dose. During the outpatient period, patients were seen in the office on weeks $1,3,5$, and 7 , and a safety phone call was conducted 30 days after last dose administration.

The study had 2 primary end points: change in body weight at 24 hours, and worsening HF at 60 days (hospitalization for HF, unscheduled emergency department or office visit for HF requiring increased or new therapy, or death). Secondary end points included changes in dyspnea, jugular venous distention, rales, edema, body weight, urine output, serum electrolyte levels, length of hospital stay after randomization, diuretics use, and patient- and physicianassessed symptoms scale.

A total of 319 patients were randomized; 78 patients were assigned to $30 \mathrm{mg}$ tolvaptan, 84 patients to $60 \mathrm{mg}$ tolvaptan, 77 patients to $90 \mathrm{mg}$ tolvaptan, and 80 patients to placebo. Mean $( \pm \mathrm{SD})$ age was $62 \pm 14,62 \pm 13,62 \pm 14$, and $60 \pm 14$ years in the 30,60, and $90 \mathrm{mg}$ tolvaptan and placebo groups, respectively. Men were $68 \%, 59.5 \%, 79.2 \%$, and $75.0 \%$ in the 30,60 , and $90 \mathrm{mg}$ tolvaptan and placebo groups, respectively $(P=0.04)$. There were no other differences between the groups except for history of percutaneous coronary intervention/coronary artery bypass graft $(P=0.02)$.

On the first day of treatment, dose-independent and significantly higher decreases in body weight were observed with tolvaptan treatment. The median (interquartile range) reductions were $-1.80(-3.85$ to -0.50$),-2.10$ $(-3.10$ to -0.85$),-2.05$ ( -2.80 to -0.60$)$, and -0.60 ( -1.60 to $0.00) \mathrm{kg}$ for tolvaptan 30,60 , and $90 \mathrm{mg}$, and placebo groups, respectively; $P=0.02,0.02$, and 0.009 for the three tolvaptan groups compared with placebo. The median (interquartile range) reductions in body weight from baseline to discharge were $-3.30(-7.30$ to -1.35$),-2.80(-5.90$ to -1.80$),-3.20$ $(-5.80$ to -1.60$)$, and $-1.90(-4.20$ to -0.50$) \mathrm{kg}$ for tolvap$\tan 30,60$, and $90 \mathrm{mg}$, and placebo groups, respectively; $P=0.006,0.02$, and 0.06 for the 3 tolvaptan groups compared with placebo.

The mean \pm SD of the first day urine output was significantly higher in all tolvaptan groups compared with placebo; $4056.2 \pm 2310.2,4175.2 \pm 2695.4,4127.3 \pm 2050.8$, and $2296.5 \pm 1134.1 \mathrm{~mL}$ for the tolvaptan 30,60 , and $90 \mathrm{mg}$, and placebo, respectively $(P=0.02,<0.001$, and $<0.001$ for the three tolvaptan groups as compared with placebo). This difference was maintained throughout the hospitalization period. Fewer tolvaptan patients had dyspnea, jugular venous distention, and peripheral edema on discharge as compared with placebo, but the difference was statistically significant only with dyspnea $(P=0.04)$. No significant improvement in the assessment scales were observed between the tolvaptan and placebo groups, and the median time between randomization and discharge was the same (4 days). There was no significant difference in worsening HF between the 2 groups during the outpatient period of the study. Diuretic use decreased in both groups after discharge, but the difference in the reduction was not statistically significant.

One day after randomization, serum $\mathrm{Na}^{+}$level increased by a mean $\pm S D$ of $2.77 \pm 3.56,3.38 \pm 4.84$, and $3.5 \pm 3.63 \mathrm{mEq} / \mathrm{L}$ in the tolvaptan 30,60 , and $90 \mathrm{mg}$ groups, compared with a decrease in sodium concentration with placebo $(-0.20 \pm 3.12 \mathrm{mEq} / \mathrm{L})$. Hyponatremia was seen in $21.3 \%$ of the patients (serum $\mathrm{Na}^{+}$concentration $<136 \mathrm{mEq} / \mathrm{L}$ ) at randomization, and they showed rapid increase and often normalization in their $\mathrm{Na}^{+}$levels that was maintained throughout the study. In post hoc analysis, total mortality was lower in the combined tolvaptan groups $(10 \%)$ compared with placebo $(22.5 \%)$ in patients with elevated blood urea nitrogen (BUN) $(>29 \mathrm{mg} / \mathrm{dL})$, but this did not reach a statistical significance $(P=0.07)$. Furthermore, total mortality was lower in the combined tolvaptan groups $(5.6 \%)$ compared with placebo $(17.8 \%)$ in patients with severe systemic congestion (presence of dyspnea, jugular venous distentions [JVD], and edema), and this was statistically significant $(P=0.03)$. However, post hoc analysis results can only be used as hypothesis generating results to guide future prospective studies. Tolvaptan did not cause any hypotension, tachycardia, worsening renal function, or abnormalities in serum $\mathrm{K}^{+}$level, however, thirst was more frequently encountered.

This study indicated that tolvaptan, on top of standard HF therapy including diuretics, increased net fluid loss resulting in lower body weight compared with standard therapy alone in patients hospitalized for HF. Tolvaptan also improved serum $\mathrm{Na}^{+}$levels in patients with hyponatremia.

In order to evaluate the effect of tolvaptan on short term symptoms and long term outcome of patients with $\mathrm{HF}^{36}$ the Efficacy of Vasopressin antagonism in Heart Failure Outcome Study with Tolvaptan (EVEREST) was conducted. ${ }^{41}$

EVEREST consisted of three studies; 2 identical studies designed to investigate the short-term effects of tolvaptan on the clinical status and symptoms and an outcome study consisting of all randomized patients, designed to investigate long-term clinical outcome. The outcome study had 2 primary end points: all cause mortality and the composite of cardiovascular death and rehospitalization for HF. The secondary outcomes included the composite of cardiovascular mortality or cardiovascular rehospitalization, incidence of cardiovascular mortality, incidence of clinical 
worsening of HF (death, hospitalization for HF, or unscheduled visit for HF), changes in body weight at day 1 , serum $\mathrm{Na}^{+}$level at day 7 or discharge in patient with a baseline serum $\mathrm{Na}^{+}$level $<134 \mathrm{mEq} / \mathrm{L}$, edema score at day 7 or discharge in those with a baseline edema, patient-assessed dyspnea in those with dyspnea at baseline, and Kansas City Cardiomyopathy Questionnaire (KCCQ) overall summary score at outpatient week 1. Tertiary end points included change in KCCQ domains at outpatient weeks 1 and 24, and at end of treatment.

EVEREST was a prospective, international, multicenter, randomized, double-blind, placebo-controlled study. ${ }^{32,41}$ Patients hospitalized for HF exacerbation were eligible to participate in the study within 48 hours of admission. The patients had to have reduced left ventricular ejection fraction ( $\leq 40 \%$ ), and signs of volume expansion. Patients with supine systolic blood pressure $<90 \mathrm{mmHg}$, serum creatinine level $>3.5 \mathrm{mg} / \mathrm{dL}$, serum $\mathrm{K}^{+}$level $>5.5 \mathrm{mEq} / \mathrm{L}$, and hemoglobin level $<9 \mathrm{~g} / \mathrm{dL}$ were excluded.

Patients were randomly assigned to receive $30 \mathrm{mg} /$ day of oral tolvaptan or placebo. The study included an inpatient treatment period and post-discharge treatment and follow up period. Patients received the study drug for a minimum of 60 days. All patients received standard HF therapy including diuretics, digoxin, angiotensin converting enzyme inhibitors (ACEI), angiotensin receptor blockers, $\beta$-blockers, aldosterone blockers, hydralazine, and/or nitrates.

The study randomized 4133 patients; 2072 received tolvaptan and 2061 received placebo. The mean $( \pm S D)$ age was $65.9 \pm 11.7$ and $65.6 \pm 12.0$ in the tolvaptan and placebo groups, respectively. Males were $73.4 \%$ and $75.4 \%$ of the patients in the tolvaptan and placebo arms, respectively. A total of 9 patients in the tolvaptan group and 6 patients in the placebo group did not receive the study medication, and hence were excluded from the safety analysis. During the study, $22 \%$ of the tolvaptan patients and $21 \%$ of the placebo patients discontinued the study medication prematurely within a median time of 8 months from randomization. Patients were followed for a median duration of 9.9 months. ${ }^{32}$

The first primary end point (all cause mortality) was not different; $25.9 \%$ vs $26.3 \%$ in the tolvaptan vs placebo groups (Hazard Ratio 0.98; 95\% CI 0.87-1.11; $P=0.68$ ). The second primary end point (death from cardiovascular causes or first hospitalization for HF) was reached in $42.0 \%$ of the patients on tolvaptan compared with $40.2 \%$ in the placebo group (hazard ratio 1.04; 95\% CI 0.95-1.14; $P=0.55)$. The composite of cardiovascular death or cardiovascular hospitalization, the incidence of cardiovascular mortality, and the incidence of clinical worsening of $\mathrm{HF}$ did not differ between the 2 groups. Improvement in the patient-assessed dyspnea score at day 1 was seen in $74.3 \%$ of tolvaptan patients with dyspnea at baseline compared with $68.0 \%$ in the placebo group $(P<0.001)$. A mean $( \pm \mathrm{SD})$ of $1.76 \pm 1.91 \mathrm{~kg}$ weight reduction at day 1 was observed in the tolvaptan group compared with $0.97 \pm 1.84 \mathrm{~kg}$ in the placebo group $(P<0.001) .{ }^{29}$ Mean $( \pm \mathrm{SD})$ serum $\mathrm{Na}^{+}$concentration increased by $5.49 \pm 5.77 \mathrm{mEq} / \mathrm{L}$ at day 7 or discharge in the tolvaptan patients with low $\mathrm{Na}^{+}$level $(<134 \mathrm{mEq} / \mathrm{L})$ compared with $1.85 \pm 5.10 \mathrm{mEq} / \mathrm{L}$ in the placebo group $(P<0.001)$. This increase was observed as early as day 1 and was maintained through 40 weeks of treatment. Mean $( \pm \mathrm{SD})$ BUN levels increased by $1.94 \pm 11.70 \mathrm{mg} / \mathrm{dL}$ at day 7 or discharge in the tolvaptan group compared with $3.30 \pm 12.16 \mathrm{mg} / \mathrm{dL}$ in the placebo group $(P<0.001)$. This difference, favoring tolvaptan, was seen as early as day 1 and persisted long after discharge. This suggests a role for tolvaptan in patients with abnormal kidney function that limits the use of other commonly used agents that are known to worsen kidney function. Mean $( \pm \mathrm{SD})$ serum creatinine level increased by $0.08 \pm 0.31 \mathrm{mg} / \mathrm{dL}$ at day 7 or discharge in the tolvaptan group compared with $0.03 \pm 0.35 \mathrm{mg} / \mathrm{dL}$ in the placebo group $(P<0.001)$. This difference was also seen at many of the long-term follow up points. ${ }^{32}$

Improvement in the edema score at day 7 or discharge was significantly higher in patients with baseline pedal edema receiving tolvaptan compared with placebo $(P=0.003)$. Physician-assessed edema was significantly improved with tolvaptan as early as day 1, and maintained through postdischarge week 4. KCCQ overall summary score was not different at outpatient week 1 , but statistically significant differences favoring tolvaptan were observed at the time of the last scheduled on-treatment assessment. The differences were in the quality of life domain $(P=0.003)$, the social limitation domain $(P=0.05)$, and the overall summary score $(P=0.02)$. This suggests a possible role for long-term tolvaptan therapy, although caution should be used in interpreting these findings given their tertiary nature. ${ }^{32}$

Adverse events were noticed in $89.0 \%$ of patients on tolvaptan compared with $86.1 \%$ of placebo. The study drug was discontinued in $6.5 \%$ in the tolvaptan group compared with $5.5 \%$ in the placebo group due to adverse effects. Thirst and dry mouth were the only side effects that were observed significantly higher in the tolvaptan group $(P<0.001$ for each). ${ }^{32}$

In the EVEREST clinical status trials, the primary end point was a composite score of changes from baseline in 
patient-assessed global clinical status and body weight at day 7 or discharge if earlier. Secondary outcomes were patientassessed changes in dyspnea at day 1 for patients with baseline dyspnea; global clinical status at day 7 or discharge; body weight at days 1 and 7 or discharge; and peripheral edema at day 7 or discharge in patients with baseline edema. ${ }^{42}$

Out of the 4133 enrolled patients, 2048 were randomized to trial A (1018 received tolvaptan, and 1030 received placebo), and 2085 to trial B (1054 received tolvaptan, and 1031 received placebo). The percentages of treatment discontinuation before day 7 (or discharge) were $2.6 \%$ and $2.4 \%$ in trial A and B, respectively. Adverse events accounted for the discontinuation of the trial in 13 patients (10 in the tolvaptan and 3 in the placebo groups) and 3 patients ( 2 in the tolvaptan and 1 in the placebo groups) in trial A and B, respectively. Demographic and baseline characteristics were similar between the tolvaptan and placebo groups in both trials. Mean ages ranged from 65.6 to 66.0 , and males were $73 \%$ to $76 \%{ }^{42}$

Tolvaptan groups had significantly greater improvement in the rank sum analysis of the composite primary outcome compared with the placebo groups; the means \pm SD were $1.06 \pm 0.43$ vs $0.99 \pm 0.44$ in trial $\mathrm{A}$, and $1.07 \pm 0.42$ vs $0.97 \pm 0.43$ in trial $\mathrm{B}$, respectively $(P<0.001$ in both trials $)$. However, no significant differences in the improvement of global clinical status at day 7 (or discharge) were observed between tolvaptan and placebo in both trials. Weight reduction was significantly higher on day 1 in the tolvaptan groups compared with placebo groups (means \pm SD were $1.71 \pm 1.81$ vs $0.99 \pm 1.83 \mathrm{~kg}$ in trial $\mathrm{A}$, and $1.82 \pm 2.01 \mathrm{vs} 0.95 \pm 1.85 \mathrm{~kg}$ in trial B, respectively; $P<0.001$ in both trials). This was also observed at day 7 (means \pm SD $3.35 \pm 3.27 \mathrm{vs} 2.73 \pm 3.34 \mathrm{~kg}$ in trial $\mathrm{A}$, and $3.77 \pm 3.59$ vs $2.79 \pm 3.46 \mathrm{~kg}$ in trial $\mathrm{B}$, respectively; $P<0.001$ in both trials). Significantly higher number of patients showed improvement in their patientassessed dyspnea score on day 1 in the tolvaptan group compared with placebo group in both trials. No statistically significant difference was noticed in the investigator-assessed pedal edema on day 7 between the tolvaptan groups and placebo groups. No significant differences in blood pressure or heart rate were observed. ${ }^{42}$

In a combined post hoc analysis of the 2 trials, improvement of dyspnea and rales (over the first 4 days), and orthopnea and JVD (during the first 3 days) was higher in the tolvaptan groups compared with placebo. Alleviation of fatigue over day 3 to 6 was better achieved with tolvaptan compared with placebo ( $P=0.02$ on day 6$)$. In patients with hyponatremia at baseline (serum $\mathrm{Na}^{+}$concentration $<134 \mathrm{mEq} / \mathrm{L}$ ), significantly greater correction of serum $\mathrm{Na}^{+}$concentration was observed with tolvaptan on day 1 and discharge. Serum $\mathrm{K}^{+}$, magnesium, osmolality, and creatinine were higher in the tolvaptan group, while BUN was lower. Tolvaptan patients had a mean reduction of furosemide dose from baseline greater than placebo, -55.8 and $-42.9 \mathrm{mg} /$ day, respectively $(P=0.002)$. An overall in-hospital mortality was $2.4 \%$ and $2.9 \%$ in the tolvaptan and placebo groups, respectively. ${ }^{42}$

A post hoc analysis was performed on the EVEREST database to specifically address the effects of tolvaptan on dyspnea relief. ${ }^{43}$ A 7-point Likert scale was used to measure patient-assessed dyspnea anytime on the first calendar day (day 1) following the first dose of study therapy. The timing of the patient-assessed dyspnea in relation to the first dose of study medication varied by patient (few hours post-dose to over 24 hours), and since patients were randomized within 48 hours from admission, the assessment was performed within 1 day to over 3 days from admission. During this time, background therapy aimed at relieving signs and symptoms is ongoing, which could have underestimated the significance of the results. Subgroup analysis was performed on pre-specified groups based on demographics (age, sex, and race), co-morbidities (ischemic and non-ischemic HF), baseline status (severity of edema, jugular venous distention, dyspnea, ejection fraction, and blood pressure), chemistry (BUN, serum creatinine, B-type natriuretic peptide, and serum $\mathrm{Na}^{+}$), and in-hospital median daily furosemide dose prior to randomization.

Out of the 4133 patients in the EVEREST trial, 3664 had baseline dyspnea and were evaluated using the patientassessed dyspnea measurement. The patients were distributed between the 2 groups; 1825 patients received tolvaptan and 1829 received placebo. Tolvaptan was associated with improvement in patient-assessed dyspnea compared with placebo (74.3\% vs $68.0 \%, P<0.0001)$. Dyspnea improved regardless of its severity at baseline, but the greatest improvement was seen in subjects with continuous dyspnea at baseline $(75.95 \%$ and $65.65 \%$ in the tolvaptan and placebo groups, respectively, $P=0.0021)$. Dyspnea improvement with tolvaptan was modest within the first 12 hours of first dose administration, and persisted for 20 hours, but the magnitude of benefit diminished with time. Tolvaptan effects on patient-assessed dyspnea at day 1 were consistent in all of the pre-specified subgroups.

This study concluded that tolvaptan's effects on dyspnea relief were greatest within 12 hours after the first dose and emphasized the need for early randomization.

In order to assess the hemodynamic effects of tolvaptan in patients with HF New York Heart Association (NYHA) 
functional class III or IV, the EffeCt of toLvaptan on hemodynamIc Parameters in Subjects with hEart failure (ECLIPSE) was conducted. It is a randomized, placebo controlled study, that enrolled patients with HF for at least 3 months with an ejection fraction $<40 \%$, on standard $\mathrm{HF}$ therapy for at least 1 month. Patients with systolic blood pressure $<90 \mathrm{mmHg}$, or serum creatinine $\geq 3 \mathrm{mg} / \mathrm{dL}$ were excluded. ${ }^{44}$

Before randomization, patients entered a baseline inpatient phase, during which they received their daily dose of concomitant background medications, and then 2 hours later, a pulmonary artery catheter was inserted. Afterwards, patients entered into 2 to 20 -hour stabilization period, after which the pulmonary capillary wedge pressure (PCWP) was measured. Patients were eligible for randomization if their PCWP was $>18 \mathrm{mmHg}$ on 2 successive readings at least 10 minutes apart and were randomized within 2 hours to receive tolvaptan 15,30 , or $60 \mathrm{mg}$, or placebo in $1: 1: 1: 1$ ratio. Those patients have advanced symptomatic HF with abnormal baseline hemodynamics, so generalizability of these data to all patients with $\mathrm{HF}$ is not certain. Hemodynamic and renal parameters were assessed at multiple points over an 8-hour assessment period during which the background diuretics and HF medications were stopped and fluid intake was restricted to $250 \mathrm{~mL}$ every 2 hours.

The primary efficacy end point was the peak change in PCWP from baseline within 3 to 8 hours after drug administration. Secondary efficacy end points included AUC for the change from baseline in PCWP and other hemodynamic parameters over the 8-hour evaluation period and renal and electrolyte parameters. A total of 181 patients were randomized; 44, 43, 46, and 48 patients received tolvap$\tan 15,30$, or $60 \mathrm{mg}$, or placebo, respectively. The mean $( \pm \mathrm{SD})$ ages were $60.3 \pm 11.7,59.7 \pm 13.4,61.0 \pm 11.9$, and $58.9 \pm 14.0$ in the tolvaptan 15,30 , and $60 \mathrm{mg}$, and placebo groups, respectively. Males were $72.7 \%$, 83.7\%, 78.3\%, and $83.3 \%$ in the tolvaptan 15,30 , and $60 \mathrm{mg}$, and placebo groups, respectively.

Tolvaptan showed a statistically significant decrease in peak change in PCWP from 3 to 8 hours after drug administration as compared with placebo; the means $\pm \mathrm{SD}$ were $-6.38 \pm 4.12(P=0.003), 15.67 \pm 4.58(P=0.044)$, $-5.71 \pm 4.35(P=0.033)$, and $-4.16 \pm 4.57$, in the tolvaptan 15,30 , and $60 \mathrm{mg}$, and placebo, respectively. The AUC for the change from baseline in PCWP over the 8-hour evaluation period was showing a statistically significant difference with only the $15 \mathrm{mg}$ tolvaptan compared with placebo. All tolvaptan doses produced statistically significantly greater changes in peak change in pulmonary artery pressure as compared with placebo, but only the 15 and $30 \mathrm{mg}$ doses resulted in statistically significant reductions in peak change in right atrial pressure. This reduction in right atrial pressure is related to volume loss from the increased urine output, which can explain the improvement in dyspnea at day 1 after tolvaptan administration that was noticed in the EVEREST trial. No significant changes in cardiac index, pulmonary vascular resistance, and systemic vascular resistance were observed. ${ }^{41}$

A dose-dependent increase in urine output was observed with tolvaptan $(P<0.0001$ for all tolvaptan groups vs placebo), and urine osmolality was significantly lower with all tolvaptan doses as compared with placebo $(P<0.0001)$. Significantly higher free water clearance was observed with all tolvaptan doses. Plasma osmolality showed significantly small increase with all tolvaptan doses. A dose-related modest increase in serum $\mathrm{Na}^{+}$concentration (mean $\pm \mathrm{SD}$ ) was observed with tolvaptan $15(1.2 \pm 2.5 \mathrm{mEq} / \mathrm{L}), 30(3.3 \pm 3.9 \mathrm{mEq} / \mathrm{L})$, and $60 \mathrm{mg}(4.6 \pm 4.9 \mathrm{mEq} / \mathrm{L})$, as compared with placebo group $(-0.7 \pm 3.2 \mathrm{mEq} / \mathrm{L})$. No significant changes in serum creatinine, $\mathrm{BUN}, \mathrm{K}^{+}$, and vital signs were observed. Tolvaptan therapy was well tolerated during this study, and there were no drug-related deaths. ${ }^{41}$

This study showed that tolvaptan administration was associated with modest favorable changes in hemodynamics in patients with advanced $\mathrm{HF}^{44}$

The potential beneficial effect of tolvaptan on remodeling was assessed in the Multicenter Evaluation of Tolvaptan Effect on Remodeling (METEOR) study, which was a multicenter, randomized, double-blind, placebo-controlled study. It evaluated the effects of long-term administration of $30 \mathrm{mg} /$ day of tolvaptan on left ventricular end-diastolic volume (LVEDV) in patients with HF and reduced systolic function. LVEDV was assessed by quantitative radionuclide ventriculography at baseline, after 1 year of therapy, and 7 days after study drug withdrawal. ${ }^{45}$

Patients included in the study were NYHA functional class II to III HF, with an ejection fraction $\leq 30 \%$ within 1 year from randomization, on standard HF therapy for at least 3 months, and with a stable dose for 2 weeks prior to enrollment.

A total of 240 patients were enrolled. The patients were randomized to receive tolvaptan (120), or placebo (120). Mean $( \pm$ SD) age was $65 \pm 12$ and $63 \pm 12$ years in the tolvaptan and placebo groups, respectively. Men were $82 \%$ and $81 \%$ in tolvaptan and placebo groups respectively. Out of the 120 patients in each group, 91 and 89 patients 
completed the study in the tolvaptan and placebo groups, respectively. At baseline, LVEDV index, left ventricular end systolic volume (LVESV) index, and left ventricular ejection fraction were similar between the tolvaptan and placebo groups. At 1 year, the mean $( \pm \mathrm{SD})$ changes in LVEDV index were $-1.78 \pm 10.7$ and $0.04 \pm 10.0 \mathrm{~mL} / \mathrm{m}^{2}$, in the tolvaptan and placebo groups, respectively $(P=0.21)$. There was also no difference in LVED index between the 2 groups 1 week after study drug withdrawal.

Changes in LVESV index and left ventricular ejection fraction were pre-specified secondary end points in this study. None of them was different in tolvaptan group as compared with placebo group at 1 year, and 1 week after study drug withdrawal. No difference was seen in blood pressure, heart rate, serum $\mathrm{Na}^{+}, \mathrm{K}^{+}, \mathrm{BUN}$, and creatinine between the 2 groups. No statistically significant differences in the Minnesota Living With Heart Failure Questionnaire score, Visual Analog Scale assessment of global status, respiratory status, subject-assessed overall treatment effect, and patientassessed global status were noticed between the tolvaptan and placebo groups.

Other outcomes were looked at, such as mortality and neurohormonal effects of tolvaptan, however they were not pre-specified. In the tolvaptan group, 5\% death rate, and 18\% HF hospitalization rate were observed, compared with $9 \%$ and $28 \%$ in the placebo group, respectively. In a time-to-event analysis, the composite of mortality or HF hospitalization favored tolvaptan $(P<0.03)$. AVP levels increased with tolvaptan treatment as compared with placebo. However, BNP levels decreased with tolvaptan and placebo, with a larger, statistically insignificant, decrease in the tolvaptan group. Urinary frequency, thirst, and dry mouth were more commonly reported with tolvaptan treatment in this trial.

This trial demonstrated that tolvaptan therapy had no significant effect on left ventricular remodeling. ${ }^{42}$ Although the outcome was disappointing as the hope for reversed remodeling did not materialize, it alleviated the concern that using selective $\mathrm{V}_{2}$ receptor antagonist might have a deleterious effect from abundant AVP stimulating $\mathrm{V}_{1}$ receptors, that could potentially result in vasoconstriction and deleterious remodeling.

The effect of tolvaptan on renal hemodynamics, water excretion, and neurohormones as compared to diuretic was assessed in a randomized, placebo-controlled crossover study, in which 14 patients with chronic HF NYHA functional class II-III, and left ventricular ejection fraction $<40 \%$ within 1 year prior to enrollment were enrolled. ${ }^{46}$ Mean $( \pm S D)$ age was $56 \pm 8$ years, and men were $71 \%$. The patients were placed on $2 \mathrm{~g} /$ day $\mathrm{Na}^{+}$diet and ACEI (other than captopril) were discontinued and replaced with captopril 15 days before the start of the study. Patients were admitted 3 days prior to the study and captopril, diuretics, $\beta$-blockers, and aspirin were discontinued. On day 1 , patients received either a single dose of placebo or $30 \mathrm{mg}$ tolvaptan and were crossed over to furosemide on day 3. On day 5, all patients received $80 \mathrm{mg}$ of furosemide. Day 2 and 4 were washout days.

Significant increases in the urine flow were noticed with tolvaptan and furosemide compared with placebo $(P<0.05)$, but there was no difference between the 2 medications. Urinary $\mathrm{Na}^{+}$excretion, $\mathrm{Na}^{+}$clearance, $\mathrm{K}^{+}$excretion, and $\mathrm{K}^{+}$ clearance were significantly higher with furosemide compared with placebo $(P<0.05)$ and tolvaptan $(P<0.05)$, and there was no difference between the latter 2. Urine osmolality decreased with tolvaptan as compared with placebo $(P<0.05)$, and tended to be lower compared with furosemide $(P=0.10)$. Renal blood flow and distal fractional reabsorption of $\mathrm{Na}^{+}$were significantly lower with furosemide compared with placebo $(P<0.05)$ and tolvaptan $(P<0.05)$, with no difference between the latter $2(P=0.19)$. Effective renal plasma flow tended to be lower with furosemide compared with placebo and tolvaptan $(P=0.053)$. There were no differences between the 3 groups in mean arterial pressure, heart rate, glomerular filtration rate, renal vascular resistance, and proximal fractional reabsorption of $\mathrm{Na}^{+}$.

No significant changes in plasma $\mathrm{Na}^{+}$levels were seen with tolvaptan and a trend for a decrease was noted with furosemide. No significant differences in serum $\mathrm{K}^{+}$concentration were noticed between the groups. Statistically significant increases in plasma renin activity and norepinephrine were seen with furosemide compared with placebo.

This study demonstrates that tolvaptan enhanced aquaresis in HF without adversely affecting hemodynamics, urinary $\mathrm{Na}^{+}$or $\mathrm{K}^{+}$excretion, serum electrolytes, or neurohumoral activation.

\section{Conclusion}

Based on the preceding review of the clinical experience with tolvaptan, its efficacy in correcting hyponatremia in patients with euvolemic or hypervolemic hyponatremia is clearly established. The available data on the safety of tolvaptan should provide health care providers the needed comfort for prescribing it although a larger experience is still required.

The unique aquaretic property of tolvaptan, as a $\mathrm{V}_{2}$ receptor antagonist, combined with the evidence documenting sustained weight loss in patients with $\mathrm{HF}$ and hypervolemia make 
it an attractive option for the management of hypervolemic hyponatremia. Theoretically, activation of $\mathrm{V}_{1}$ receptors by the abundant AVP may lead to increased systemic vascular resistance and hemodynamic deterioration. However, the lack of detrimental effect by tolvaptan on remodeling in patients with systolic HF and the neutral effect on outcomes should alleviate the concern that the use of selective $\mathrm{V}_{2}$ receptor antagonists in systolic HF may not be advisable. The concern that the use of selective $\mathrm{V}_{2}$ receptor antagonist may be detrimental in HF has been alleviated.

Despite the neutral effect of tolvaptan on outcomes among patients with systolic HF the available safety records provide a basis for its use to correct moderate to severe hyponatremia among outpatients with systolic HF. The decision to prescribe tolvaptan in this setting is not based on any evidence of improvement in symptoms or outcome but largely dictated by the comfort level of health care providers. The notion that in patients with systolic HF and volume overload, tolvaptan may provide benefit by either replacing or reducing the dose of diuretics is not supported by the available data. The lack of neurohormonal activation, however, combined with the lack of a negative effect on electrolytes support further research effort for this indication.

It should be clearly acknowledged that failure of tolvaptan to improve outcome among patients hospitalized with decompensated systolic HF may entirely be explained by failure to target hyponatremic patients. Thus, the potential beneficial effects of tolvaptan in improving outcomes in patients with decompensated HF associated with hyponatremia have not been explored yet.

\section{Disclosure}

The authors declare no conflicts of interest.

\section{References}

1. Ghali JK. Mechanisms, risks, and new treatment options for hyponatremia. Cardiology. 2008;111:147-157.

2. Renneboog B, Vendemergel X, Manto MN, et al. Mild chronic hyponatremia is associated with falls, unsteadiness and attention deficits. Am J Med. 2006;119:71e1-71e8.

3. Sandhu HS, Gilles E, DeVita MV, et al. Hyponatremia associated with large bone fracture in elderly patients. Int Urol Nephrol. 2009;41: 733-737.

4. Kinsell S, Moran S, Sullivan MO, et al. Hyponatremia independent of osteoporosis is associated with fracture occurrence. Clin J Am Soc Nephrol. 2010;5:275-280.

5. Gankam Kengne F, Andres C, Sattar L, et al. Mild hyponatremia and risk of fracture in the ambulatory elderly. QJM. 2008;101:583-588.

6. Waikar SS, Mount DB, Curhan GC. Mortality after hospitalization with mild, moderate, and severe hyponatremia. Am J Med. 2009;122: $857-865$.
7. Wald R, Jaber BL, Price LL, Upadhyay A, Madias NE. Impact of hospital-associated hyponatremia on selected outcomes. Arch Intern Med. 2010;170:294-302.

8. Sajadieh A, Binici Z, Mouridsen MR, et al. Mild hyponatremia carries a poor prognosis in community subjects. Am J Med. 2009;122: 679-686.

9. Gheorghiade M, Abraham WT, Albert NM, et al. Relationship between admission serum sodium concentration and clinical outcomes in patients hospitalized for heart failure: an analysis from the OPTIMIZE-HF registry. Optimize-HF Investigators and Coordinators. Eur Heart $J$. 2007;28:980-988.

10. Ghali JK. Hyponatremia in heart failure: a call for redefinition. Eur Heart J. 2007;28:920-921.

11. Decaux G. Is asymptomatic hyponatremia really asymptomatic? Am J Med. 2006;119(7A):S79-S82.

12. Guyton AC. The body fluids and kidneys. In: Guyton AC, Hall JE, editors. Textbook of Medical Physiology. Philadelphia (PA): WB Saunders Company; 2006:291-414.

13. Oliet SH, Bourque CW. Mechanosensitive channels transducer osmosensitivity in supraoptic neurons. Nature. 1993;364:341-343.

14. Wade CE, Keil LC, Ramsay DJ. Role of volume and osmolality in the control of plasma vasopressin in dehydrated dogs. Neuroendocrinology. 1983;37:349-353.

15. Schrier RW. Water and sodium retention in edematous disorder: role of vasopressin and aldosterone. Am J Med. 2006;119:S47-S53.

16. Schrier RW, Berl T, Anderson RJ. Osmotic and nonosmotic control of vasopressin release. Am J Physiol. 1979;236:F321-F332.

17. Mitchell LD, Barron K, Brody MJ, et al. Two possible actions for circulating angiotensin II in the control of vasopressin release. Peptides. 1982;3:503-507.

18. Thibonnier M, Conarty DM, Preston JA, et al. Molecular pharmacology of human vasopressin receptors. Adv Exp Med Biol. 1998;449:251-276.

19. Ali F, Guglin M, Vaitkevicius P, et al. Therapeutic potential of vasopressin receptor antagonists. Drugs. 2007;67:847-858.

20. Nielsen S, Kwon TH, Christensen BM, et al. Physiology and pathophysiology of renal aquaporins. J Am Soc Nephrol. 1999;10:647-663.

21. Tanoue $A$, Ito $S$, Honda $K$, et al. The vasopressin $V_{1 B}$ receptor critically regulates hypothalamic-pituitary-adrenal axis activity under both stress and resting conditions. $J$ Clin Invest. 2004;113:302-309.

22. Samsca (tolvaptan) [prescribing Information]. Tokyo, Japan: Otsuka Pharmaceutical Co, Ltd. 2009. http://www.samsca.com/pdf/samscaPI. pdf. Accessed May 2, 2010.

23. Yamamura Y, Nakamura S, Itoh S, et al. OPC-41061, a highly potent human vasopressin V2-receptor antagonist: Pharmacological profile and aquaretic effect by single and multiple oral dosing in rats. $J$ Pharmacol Exp Ther. 1998;287:860-867.

24. Shoaf SE, Wang Z, Bricmont P, et al. Pharmacokinetics, pharmacodynamics, and safety of tolvaptan, a nonpeptide AVP antagonist, during ascending single-dose studies in healthy subjects. J Clin Pharmacol. 2007;47:1498-1507.

25. Hauptman PJ, Zimmer C, Udelson J, et al. Comparison of two doses and dosing regimens of tolvaptan in congestive heart failure. J Cardiovasc Pharmacol. 2005;46:609-614.

26. Hirano T, Yamamura $Y$, Nakamura $S$, et al. Effects of the $V_{2}$ receptor antagonist OPC-41061 and the loop diuretic furosemide alone and in combination in rats. J Pharmacol Exp Ther. 2000;292:288-294.

27. Shoaf SE, Mallikaarjun S. Effect of ketoconazole and grapefruit juice, CYP3A4 inhibitors, on the pharmacokinetics of tolvaptan, a non-peptide vasopressin antagonist. Clin Pharmacol Ther. 2008;83:S57.

28. Mallikaarjun S. Effect of rifampin, CYP3A4 inducer, on the pharmacokinetics and pharmacodynamics of tolvaptan, a non-peptide vasopressin antagonist. Clin Pharmacol Ther. 2008;83:S57.

29. Shoaf SE, Elizari MV, Wang Z, et al. Tolvaptan administration does not affect steady state amiodarone concentrations in patients with cardiac arrhythmias. J Cardiovasc Pharmacol Ther. 2005;10:165-171. 
30. Shoaf SE, Bramer SL, Bricmont P, et al. Pharmacokinetic and pharmacodynamic interaction between tolvaptan, a non-peptide AVP antagonist, and furosemide or hydrochlorothiazide. J Cardiovasc Pharmacol. 2007;50:213-222.

31. Shoaf SE, Wang Z, Mallikaarjun S, et al. Lack of clinically significant interaction between steady state tolvaptan and digoxin in healthy volunteers. Clin Pharmacol Ther. 2004;75:P37.

32. Konstam MA, Gheorghiade M, Burnett JC, et al. Effects of oral tolvaptan in patients hospitalized for worsening heart failure, the EVEREST outcome trial. JAMA. 2007;297:1319-1331.

33. Okita K, Sakaida I, Okada M, et al. A multicenter, open-label, doseranging study to exploratively evaluate the efficacy, safety, and dose-response of tolvaptan in patients with decompensated liver cirrhosis. J Gastroenterol. 2010;45:979-987.

34. Gheorghiade M, Gottlieb SS, Udelson JE, et al. Vasopressin $V_{2}$ receptor blockade with tolvaptan versus fluid restriction in the treatment of hyponatremia. Am J Cardiol. 2006;7:1064-1067.

35. Schrier RW, Gross P, Gheorghiade M, et al. Tolvaptan, a selective oral vasopressin $\mathrm{V}_{2}$ receptor antagonist, for hyponatremia. $N$ Engl J Med. 2006;355:2099-2112.

36. Berl T, Quittnat-Pelletier F, Verbalis J, et al. Oral tolvaptan is safe and effective in chronic hyponatremia. J Am Soc Nephrol. 2010;21: 705-712.

37. Josiassen RC, Goldman M, Jessani M, et al. Double-blind, placebocontrolled, multicenter trial of a vasopressin $\mathrm{V}_{2}$ receptor antagonist in patients with schizophrenia and hyponatremia. Biol Psychiatry. 2008; 64:1097-1000

38. Gheorghiade M, Niazi I, Ouyang J, et al. Vasopressin $V_{2}$ receptor blockade with tolvaptan in patients with chronic heart failure, results from a double-blind, randomized trial. Circulation. 2003;107:2690-2696.
39. Gheorghiade M, Gattis WA, Barbagelata A. Rationale and study design for a multicenter, randomized, double-blind, placebo-controlled study of the effects of tolvaptan on the acute and chronic outcomes of patients hospitalized with worsening congestive heart failure. Am Heart J. 2003;145:S51-S54.

40. Gheorghiade M, Gattis WA, O'Connor C, et al. Effects of tolvaptan, a vasopressin antagonist, in patients hospitalized with worsening heart failure: a randomized controlled trial. JAMA. 2004;291:1963-1971.

41. Gheorghiade M, Orlandi V, Burnett JC, et al. Rationale and design of the multicenter, randomized, double-blind, placebo-controlled study to evaluate the efficacy of vasopressin antagonism in heart failure: outcome study with tolvaptan (EVEREST). J Card Fail. 2005;11:260-269.

42. Gheorghiade M, Konstam MA, Burnett JC, et al. Short-term clinical effects of tolvaptan, an oral vasopressin antagonist, in patients hospitalized for heart failure, the EVEREST clinical status trials. JAMA. 2007;297:1332-1343.

43. Pang PS, Konstam MA, Krasa HB, et al. Effects of tolvaptan on dyspnoea relief from the EVEREST trials. Eur Heart J. 2009;30:2233-2240.

44. Udelson JE, Orlandi C, Ouyang J, et al. Acute hemodynamic effects of tolvaptan, a vasopressin $\mathrm{V}_{2}$ receptor blocker, in patients with symptomatic heart failure and systolic dysfunction: an international, multicenter, randomized, placebo-controlled trial. JACC. 2008;52:1540-1545.

45. Udelson JE, McGrew FA, Flores E, et al. Multicenter, randomized, double-blind, placebo-controlled study on the effect of oral tolvaptan on left ventricular dilation and function in patients with heart failure and systolic dysfunction. JACC. 2007;49:2151-2159.

46. Costello-Boerrigter LC, Smith WB, Boerrigter G, et al. Vasopressin2-receptor antagonism augments water excretion without changes in renal hemodynamics or sodium and potassium excretion in human heart failure. Am J Physiol Renal Physiol. 2006;290:F273-F278.

\section{Publish your work in this journal}

The International Journal of Nephrology and Renovascular Disease is an international, peer-reviewed open-access journal focusing on the pathophysiology of the kidney and vascular supply. Epidemiology, screening, diagnosis, and treatment interventions are covered as well as basic science, biochemical and immunological studies. The journal welcomes

\section{Dovepress}

original research, clinical studies, reviews \& evaluations, expert opinion and commentary, case reports and extended reports. The manuscript management system is completely online and includes a very quick and fair peerreview system, which is all easy to use. Visit http://www.dovepress.com/ testimonials.php to read real quotes from published authors. 